place the names of such men as Dr. Blundeil, Dr Goorbl, Dr. Davis, and Dr. John Hull of Manchester, against any autho. rify that could be brought forward against the operation.

The President (Dr. Hamitron) considered the case lighly creditable to the Gentleman who had bronght it forward. There was ouly one thing which he had omitted to employ, and that was, to have administered glysters of chicken broth!!

\section{ANOTHER SUCCESSFUL CASE OF TRANSFUSION.}

\section{To the Editor of THE LANCET.}

SIR,-The subject of transfusion having excited a generkl and intense interest, $I \mathrm{am}$ induced 10 forward to you the fol. lowing case, in the relation of which $I$ shall purposely avoid physiological remarks, and confine myself to tacts that $I$ ain fully prepared to substantiate (if necessary) bv unprejudiced authority.

On Wednesday, the 17 th inst., about 11 a. $\mathrm{m}$., I was called in haste to Mrs. Bates, of No. 9, Great St. Andrew's-street, whom I found in a state of extreme exhaustion from uterine hæmorrhage. I learnt that she had aborted (at the end of the third month) at one o'clork in the morning, and that the flooding had been ever since copious and incessant. Finding, upon examination, that the toetus, placenta, and membranes, had been expelled, $I$ directed the application of cold water, and after an hour $I$ had the satisfaction to find that the hæmorrharge had ceased, and I took leave of her. Upon renewing my visit three hours afterwards, 1 found her still more sunken, and although the hæmornhage was not renewed, I could perctive the prostration increase, even as I sat by her. I now administered landanum and brandy with that unsparing liberality, of which but too much experience in these urgent cases has taught me the propriety and necessity. The hours rolled on, but my poor patient's system replied not to the repeated use of the ce powerful stimulants; life was fast ebbing, and nature incapable of rallying. Her countenance was blanched and cadaverous; he: eyes, sunken and dim, were partially covered by the falling of the upper lids; her lips paie and guivering; the extre. mities cold; the surface of the body covered with a chilling moisture; the pulse just pereeptible enough to be tound fut. tering and irregular, beating (as well as I conld ascertain) more than 140 strokes in a minute. She was extremely restless, and every now and then a cessation of ne pulse, a livid hne of the tace, and motionless position of the bolly, marked a temporary state of syncope, which I more than once mistook for death. Notuitl. standing the flooding had ceased, eleven hours were spent in attempts to induce reaction, but in vain; not a solitary indication of it was manifested during this time, but the patient continued gradually to sink, until but faint signs of life remained.

The operation of transfusion now appeared to me the only means of saving the patients life, and I therefore immediately called in the assistance of my friend Mr. Scott, of whose ingenious apparatus for tran fusion of blond I had just heard. This gentleman fully con. curred in my opinion of the extreme darger of the case, and of the atter ineffcacy of all medicinal agents, but he rather yielded to, than approved of, my proposal to try the operation of transfic. sion, as he regarded the life of the patient too near its extinction to be capa. ble of resuscitation. I lost no time, how. ever, in procuring, from Mr. Read, the necessary instruments, and four ounces of blood were injected into the median vein of the right arm. In a few minutes the pulse became stronger and more apparent, and the comntenance lost much of its death-like appearance; the surtare became warmer, the eyes intelligent and inquiring, and in a quarter of an hour from the operation, she raised herself upon her ellsows and asked for drink; the circulation gradually recovered, and steadily rose in firmness, whilst it diminished in velocity, and after less than an hour, we left her with a pulse not weaker, probably, than in health, and equal in its beat, striking 120 strokes in a minute. In fine, from this moment she rallied, and her convalescence has been uninterrupted.

Such, Sir, is a brief sketch of the most gratifying case that has ever rewarded my professional solicitude; and if there lives a sceptic to the powers of transfit. sion, he cannot receive a more just reward, than in being for ever shat ont by his prejudices from the enjoyment of that satisfaction which results from so closely contributing in restoring a wife to her lusband and a mother to her childiren.

In conclusion, I cannot speak too highly of the ingenuity displayed by Mr. Read in the apparatus I employed ; for however formidable and diffeult the opera- 
thon may have hitherto seemed, it may be performed by this instrument with the greatest ease.

$$
\text { I am, Sir, }
$$

Your obedient huuble servant, Jos. RalPh.

\section{Leicester-square,} May 23, 1826.

\section{To the Editor of THE LANCET.}

$$
\text { Sik, }
$$

It requires a public-spirited individual like yourse'f, aided by that mighty eugine the Press, which you are so successfully wielding in the cause of medical liberty, to correct the glaring abuses at present existing in the various departments of the profession. I beg to thank you individually, and in the name of many of my arguaintances, for the indefatigable perseverance you have shown in the callse, and tunst that you will go on and continue your praiseworthy exertions, till a complete reform has been obtained.

I have observed $\mathrm{with}$ great interest the varions proceedings that have taken place, pupecially as to the abuses in the Collecre of Surgeons, and have read with no little astonishment the "Refutation,' (if such it can be called,) put forth by the Conncii and published in your lulst Number. I do not mean to follow the Council through their tedions and extraordinary paper, but state that my attention has been more particilarly arrested in its pel usal by the degrading and contemptnous manner in which the General Practitioners are spohen of, and the scandalous assertion, that were the affairs of the College to ge: into the hands of the members at large, there wonld at once be an end to every thing like "Sonnd chirurgical knowlerge," and the annibilation of all rule and regulat ity, as if, forsooth, General Practitioners (the most numerous and by far the most useful body in the profession) cease to be surgtons and honourable men when they send ont medicines to their patients. The true meaning of the thing is this - that Messrs. the senile council and examinators would no longer have the honours and good things they at present enjoy, as the "Riling powers;" for, were a new chatter granted, the members of the Col. lege would immediately remove these sulperannuated worthies and substitute efficient men.

But I would particularly beg the attention of the members of the college who are general practitioners, to the two Iast rlanses but one of the Conncil's " Refirtation" which you have already very properly animadverted npon, and perhaps you will allow me to tronecribe them again as they ought never to be forgotten during the present contest, and cannor be too much held up to tile view of the degraded members. They say "It is represented" (and very truly too, " that the constitution of the College has been the cause of the alleged injuries and grievances. The evident object of this representation, is the subversion of the present government of the College, and the substitution of elections to offices of control and responsibility, by nembers, who for the most part exercise the professions of apothecaries and accouchenrs. There can be little doubt that in the event of such an innovation, the institution would soon cease to be a College of Surgeous or of Surgery, and a system of contimual intrigue and cabal amonst the protession in general would be introduced."

Now, I would ask, whether the Conncil are borne out, by farts and experience, in their most disrespectfiul and unblushing asmertion? or whether the effects the council so much dread, in $t^{\prime}$ etr anxwety for the u'lfare of the College, have ensued in other Colleges of Surgeons, not inferior I believe to that of London, either in character or abilities, and certainly much superior as to the extent of study and qualifications necessary in candidates for their diplomas-I allude to the Colleges of Edinburgh and Glasgow. The presilent, examiners, and other office bearers, are, withont any exceptions I believe, General Practitioners, prescribing and sending out medecines for their patients; but 1 have yet to learn that these royal bodies are govenned by " intrigue and "abal," or that they are likely soon " to cease to be Colleges of Surgeons or of Surgery."

But as these supercilious and fastidious old gentlemen, Messis. the Conncil, seem to eye the General Practiones with such thorongh contempt, and look down npon them as unworthy of their notice, I trust that the latter will on all occasions treat the Conncil and their coadjutors with the respect they so much deserve, and will, with their patients, keep at as respectable a distance as possible. It would be perfect contamination for one of these elevated "pure suigeons" to meet in con. sultation a General Practitioner, the fomenter of "intrigne and cabal," and indeed it would be considesed a piece of very great presumption in the latter to thrust his ummannerly presence on the prond anistocracy of the profession. " $O$ procul este profani," \&c. And I have no doubt but a fee introduced by a surgeonapothecary and accoucheur would be absolutely refused, as it would smell of physic! a commodity these scientific surgeons thank God that they haye had nothing to do 
with, and know nothing of ! which I most / is no mle nithout an exception-such a readily believe, judging by the mechanical subterfige, bowever, I want not, but farrago of ingredients I have often seen aver that where the application of phar. huddled into their monstrous prescriptions coal has been followed by a sedative that would disgrace the merest Tyro. effect, it (the effect) has been in contra.

I therefore hope the General Practi- distinction only to the excesuive excitetioner will in future know how to keep ment occasioned by chymical stimuli, and his place, and not dare to intrude upon his therefore apparent, not real, or in other betters, especially as there is alundance words, by the substitution of a less netive of enlightened and scientific surgeons in stimulus the exritement ocrasioned by a London, who will think it no disgrace to more powerful one degenerates, and a join in consultation the surgeon-apothe- comparatively sedative effect is the consecary and accoucheur.

A General Practitioner.

\section{To the Editor of The LANCET.}

Sir,-In looking over the contents of your $137 \mathrm{th}$ number, which this day came to hand, I found a communication from Mr. Gonlson " on the uses of charcoal in sloughing phagedena;" and as the subjoct had previously engaged the pens of Mr. Wansbrongh and myself, I anxionsly turned to the page, expecting that Mr.G. had favoured us with a solution of the point at issue, by throwing some light on the obscurity in which the subject was, and still is, involved. After reading the first half dozen lines, I flattered myself that my hopes were realized, and indeed any one reflecting on the observations therein contained, would conclude that the anthor of them was abont (to use his own expression) setting the matter in its proper light. The sequel, however, proves that we are constantly exposed to disappointments; and finely illustrates the fable of the mountain in labour. As the point at issue was the rationale of the salutary action of charcoal on ulcerated surfaces, I shall beg leave to address a few words to your numerous and impartial readers in reply to the objections raised by $M r$. G. against the opinion $I$ advanced in a former number of THE LANCET, under the signature of ** $\mathrm{M}-$; first premising, that $I$ beg to refer them to what $I$ then stated, in consequence of an insinuation expressed in the latter part of Mr. G.'s communication, tending to con. vey an impression that I condemned in to to the $u s e$ of charcoal in slonghing phagedena, whereas the benefit derived trom it never admitted of doubt, and consequently did not enter into the subject under discnssion. The principal, nay, the only objection which Mr. G. starts against the mechanical action of charcoal, is founded on the fact, or rather as I silall show on the supposition, "that it has chiefly (in his practice perhaps) shown its good effects in cases where applications of a stimulating nature aggravated the disease." To this I may reply there quence. Although I am not ignorant of the sedative effects of charcoal upon the nervous system, when taken into the circulation throngh the medium of the chy. lopoietic viscera, yet when the insoluble nature of charcoal is considered, will any one, with the least pretension to physiolo. gical knowledge, believe it to have a direct sedative effect on the surface of an ulcer. The following question I cannot pass over withont notice-" Who that is conve sant witl chy mistry, will maintain that it (charcoal) can have no chymical action on the surfice of an nicer?" Without directly answering in the affir. mative, I will maintain that until ehy. mical action shal $/$ have been demonstrated, by chymical reagents, to have taken place, it is mire plansible to consider its salu. tary effect entirely mechanical; and assuredly more philosophical, for who wonld attempt to explain an effect by an unknown cause, when an apparent one, which possibly may be true, is within reach.

After having denounced is ignorant of the important properties of charcoal, $\mathrm{Mr}$. G. pasies on to acquaint us of what every tyro in the profestion is experted to be aware, and which had it not beentrespassing too minch on your valuable pages, Mr. Wansbrough would have, no doubs, detailed, in order that his theory might have received the support $u$ hich is trequently derived from analosical reasoning.

With all defierence, I cannot conclude without reminding Mr. G. that, although argument, conducted with temperate lan. grage, is the great and only sure means of eliciting truth, it is at the same time a waste of time and paper when not direrted to, and if pos-ible followed by, a satis. factory conclusion. With this impression, and as I have made a full exposition of my ideas on the sulyject, I shall close the discussion.

Not to snbject myself a second time to the imputation of a breach of duty, and relying on your liberality to give this in. sertion in the columns of your widely. extended Journal, I rem tin yours,

Kingston, May 10, 1826. 